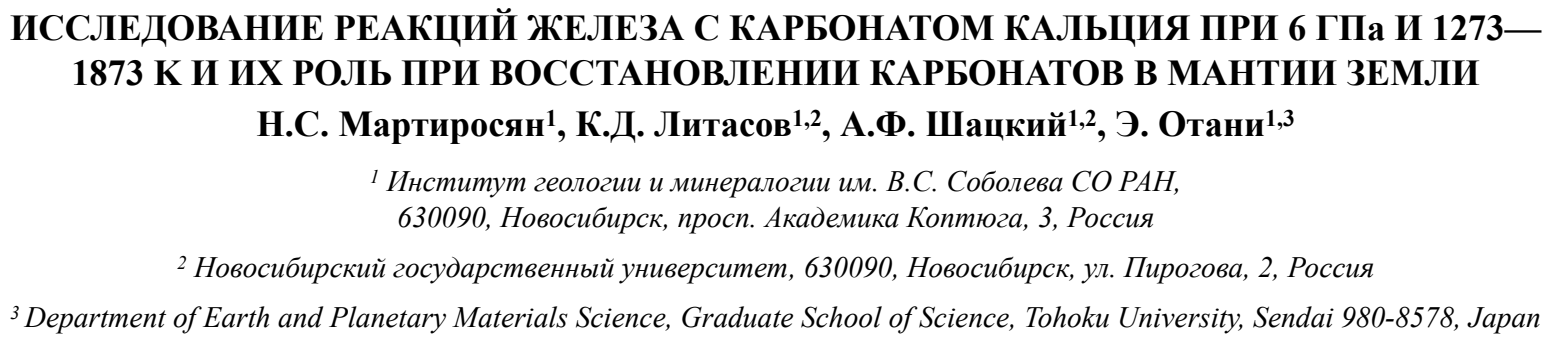

\begin{abstract}
Представлены результаты экспериментального исследования реакций в системе $\mathrm{Fe}-\mathrm{CaCO}_{3}$ при давлении 6 ГПа и различных температурах от 1273 до 1873 К. Данная система отражает возможный механизм окислительно-восстановительного взаимодействия, происходящего в погружающейся субдукционной плите на контакте с восстановленной мантией, и вариант взаимодействия на границе ядро-мантия. Анализ образцов показал, что изучаемая реакция сопровождается образованием карбонатитового расплава, а также карбида $\left(\mathrm{Fe}_{3} \mathrm{C}\right)$ и кальциевого вюстита $((\mathrm{Ca}, \mathrm{Fe}) \mathrm{O})$, которые в зависимости от условий опытов образуют твердые или жидкие фазы. При 6 ГПа плавление карбоната кальция в системе, содержащей железо, происходит в интервале температур 1473-1573 К, что согласуется с исчезновением арагонита в сложных карбонатсодержащих системах. Состав расплава не меняется под влиянием металлического железа и фактически соответствует чистому $\mathrm{CaCO}_{3}$. Вдоль мантийной адиабаты или при немного больших температурах описываемый карбонатный расплав сосуществует в равновесии с металлическим железом или кальциевым вюститом и объясняет совместное нахождение включений карбонатов и железа в литосферных и сверхглубинных алмазах.
\end{abstract}

Мантия, карбонат, субдукиия, железо, окислительно-восстановительное состояние, плавление, эксперимент, высокие давления.

\title{
REACTIONS OF IRON WITH CALCIUM CARBONATE AT 6 GPa AND 1273-1873 K: IMPLICATIONS FOR CARBONATE REDUCTION IN THE DEEP MANTLE
}

\section{N.S. Martirosyan, K.D. Litasov, A.F. Shatskiy, and E. Ohtani}

Experimental data on $\mathrm{Fe}-\mathrm{CaCO}_{3}$ interaction at $6 \mathrm{GPa}$ and $1273-1873 \mathrm{~K}$ are presented. The system models the hypothetical redox interaction in subducting slabs at the contact with the reduced mantle and a putative process at the core-mantle boundary. The reaction is accompanied by carbonatite melt formation. It also produces $\mathrm{Fe}_{3} \mathrm{C}$ and calcium wüstite, which form solid or liquid phases depending on experimental conditions. In iron-containing systems at $6 \mathrm{GPa}$, calcium carbonate melts in the range $1473-1573 \mathrm{~K}$, which is consistent with aragonite disappearance from complex carbonate systems. The composition of calcium carbonate liquid is not influenced by metallic Fe. It corresponds to nearly pure $\mathrm{CaCO}_{3}$. Along the mantle adiabat or at slightly higher temperatures, nearly pure $\mathrm{CaCO}_{3}$ coexists with metallic iron or calcium wüstite. This hypothesis explains the coexistence of metallic iron and carbonate inclusions in lithospheric and superdeep diamonds.

Mantle, carbonate, subduction, iron, redox state, melting, experiment, high pressures

\section{ВВЕДЕНИЕ}

Частичное плавление карбонатизированных перидотитов и эклогитов приводит к образованию кимберлитов, карбонатитов, связанных с ними магм, а также играет значительную роль в образовании MORB и OIB [Gudfinnsson, Presnall, 2005; Dasgupta, Hirschmann, 2006; Литасов, 2011]. Таким образом, изучение $\mathrm{Mg}-\mathrm{Ca}-\mathrm{Fe}$ карбонатов, щелочных карбонатов и карбонатитовых расплавов при высоких давлениях является важнейшей задачей для понимания динамики процессов в мантии [Добрецов, Шацкий, 2012; Соболев и др., 2015].

Основным источником карбонатов и карбонатитовых расплавов в мантии является субдукция океанических плит [Grassi, Schmidt, 2011; Litasov et al., 2013b; Staudigel, 2014]. Также они могут формироваться на границе ядро-мантия, в случае если ядро выделяет некоторое количество углерода, растворенного в расплавленной металлической фазе [Добрецов, Шацкий, 2012; Wood et al., 2013]. В действи- 
тельности, какой бы ни был источник карбонатов и карбонатитовых расплавов, их стабильность в большой степени зависит от окислительно-восстановительного (OB) потенциала мантии и от взаимодействий с силикатами и летучими компонентами, такими как вода [Ballhaus, Frost, 1994; Frost, McCammon, 2008; Foley, 2011; Rohrbach, Schmidt, 2011; Litasov et al., 2014; Рагозин и др., 2014].

Судьба субдуцированных карбонатов является важным вопросом для глубинной геодинамики, который активно изучается [Dasgupta, 2013; Palyanov et al., 2013; Safonova et al., 2015]. Частичная декарбонатизация на глубине около 150 км под вулканическими дугами, плавление в переходном слое или в нижней мантии могут привести к образованию щелочно-карбонатитового или карбонатно-силикатного расплава, способного накапливаться вдоль границы плиты с мантией. В результате могут образовываться карбонатитовые диапиры, которые могут перемещаться к поверхности благодаря плавучести и при помощи механизма растворения-осаждения [Litasov et al., 2013b; Safonova et al., 2015; Похиленко и др., 2015], характерного для движения твердых и жидких включений в экспериментах с солями или даже алмазом [Чепуров и др., 1998; Федоров и др., 2005]. Однако подвижность карбонатного расплава в глубинных частях верхней мантии, в переходном слое и нижней мантии может значительно сократиться из-за ОВ взаимодействия с содержащими металлическое железо перидотитами [Rohrbach, Schmidt, 2011; Palyanov et al., 2013]. С другой стороны, тугоплавкие карбонаты (арагонит, магнезит), сохраняющиеся после частичного плавления плиты и формирования карбонатитового расплава, также будут восстанавливаться с образованием алмазов или карбидов [Pal'yanov et al., 1999, 2002; Dasgupta, Hirschmann, 2010; Rohrbach, Schmidt, 2011; Palyanov et al., 2013], поскольку фугитивность кислорода в мантии на глубине более 230 км соответствует буферу железо-вюстит [Ballhaus, Frost, 1994; Frost, McCammon, 2008; Foley, 2011; Rohrbach, Schmidt, 2011], тогда как область стабильности карбонатов на две-три логарифмические единицы превышает его $\left(\Delta \lg f_{\mathrm{O}_{2}}(\mathrm{IW})=2-3\right.$ лог.ед.) [Stagno et al., 2011 ].

Динамические и кинетические параметры процесса взаимодействия окисленного карбонатного вещества с восстановленными перидотитами мантии необычайно важны для исследования глобального цикла углерода и его распределения в недрах Земли. Важнейшими компонентами, вступающими в реакцию на границе плита-мантия, являются карбонаты и окисленные силикаты со стороны океанической плиты и восстановленные силикаты с небольшим количеством самородного железа, со стороны мантии. Кроме вышеперечисленных компонентов немаловажное влияние на баланс металлического $\mathrm{Fe}$ и ОВ условия в мантии могут оказывать сульфидные минералы и расплавы. Распространенность сульфидных включений в алмазах и других мантийных минералах указывает на особую значимость твердых или расплавленных сульфидов по сравнению с FeNi-расплавом и карбидами [Deines, Harris, 1995; Richardson et al., 2001; Тэйлор, Ли, 2009].

Систему карбонат-металл-силикат-сульфид необходимо исследовать в сложных петрологических системах, однако полученные подобным образом данные сложно интерпретировать с точки зрения термодинамики и кинетики без понимания процессов фазообразования, окисления и восстановления в простых системах. В первом приближении окисленный компонент плиты может быть представлен карбонатом, а восстановленный реагент мантии или ядра - металлическим железом или FeO. B данной статье описан начальный этап экспериментальных работ, посвященных исследованию взаимодействия карбонатов с мантией. Была изучена система $\mathrm{Fe}-\mathrm{CaCO}_{3}$ при давлении 6 ГПа и температуре 1273$1873 \mathrm{~K}$, проанализированы взаимоотношения фаз выше и ниже солидуса и сделаны выводы, касающиеся динамики процесса субдукции в мантии Земли.

\section{МЕТОДЫ ИССЛЕДОВАНИЯ}

Эксперименты проводились с использованием гидравлических прессов с максимальной нагрузкой 3000 и 1500 т в Университете Тохоку (Япония). 3000-тонный пресс имел DIA-конфигурацию с направлением сжатия [001], тогда как нагрузка второго пресса на ячейку высокого давления осуществлялась по направлению [111] [Shatskiy et al., 2011]. В опытах использовался многопуансонный блок типа Каваи с внутренней ступенью из восьми WC пуансонов со срезанными углами, сечение которых составляло 12 мм. Для оптимизации распределения напряжений в пуансонах и запирания сжимаемого объема применяли деформируемые уплотнения (прокладки) из пирофиллита с шириной и толщиной 4.0 мм.

Схема ячейки высокого давления показана на рис. 1. Ячейку изготавливали из полуспеченной керамики из $\mathrm{ZrO}_{2}$ марки OZ-8C Mino Yogyo Co., Ltd [Shatskiy et al., 2010]. Нагрев образца осуществляли с помощью цилиндрического графитового нагревателя длиной 11 мм, с внешним и внутренним диаметрами 4.5 и 4.0 мм соответственно. В ячейке размещали 12 образцов, расположенных симметрично относительно спая термопары (см. рис. 1).

Температуру контролировали с помощью $\mathrm{W}-\mathrm{Re}_{3-25}$ \% термопары, размещенной в центре ячейки и изолированной от нагревателя трубкой из $\mathrm{Al}_{2} \mathrm{O}_{3}$. Влияние давления на ЭДС термопары не учитывали. Максимальные радиальные и осевые градиенты вдоль образцов не превышали 5 и 10 K/мм соответственно [Shatskiy et al., 2013] (см. рис. 1). 
Рис. 1. Схема экспериментальной ячейки с одновременной загрузкой 12 образцов в капсулы из Fe, BN или MgO.

Температурный градиент между спаем термопары в центре ячейки и границей капсулы (В и С) составляет $20-30$ К для расстояния центр-В и $25-35$ К для центрС. Наблюдается небольшая разница температур (менее $10 \mathrm{~K}$ ) между образцами на уровне 1 (высокотемпературном) и уровне 2 (низкотемпературном). $1-\mathrm{ZrO}_{2}$, 2 - графит, 3 - $\mathrm{MgO}, 4$ - капсула.

Калибровку давления при комнатной температуре проводили, фиксируя измерение электросопротивления в момент фазовых переходов в Ві и Ва [Shatskiy et al., 2011]. Калибровку по давлению при 1373 К осуществляли с помощью фазовых превращений в $\mathrm{SiO}_{2}$ (кварц-коэсит) [Bose, Ganguly, 1995] и

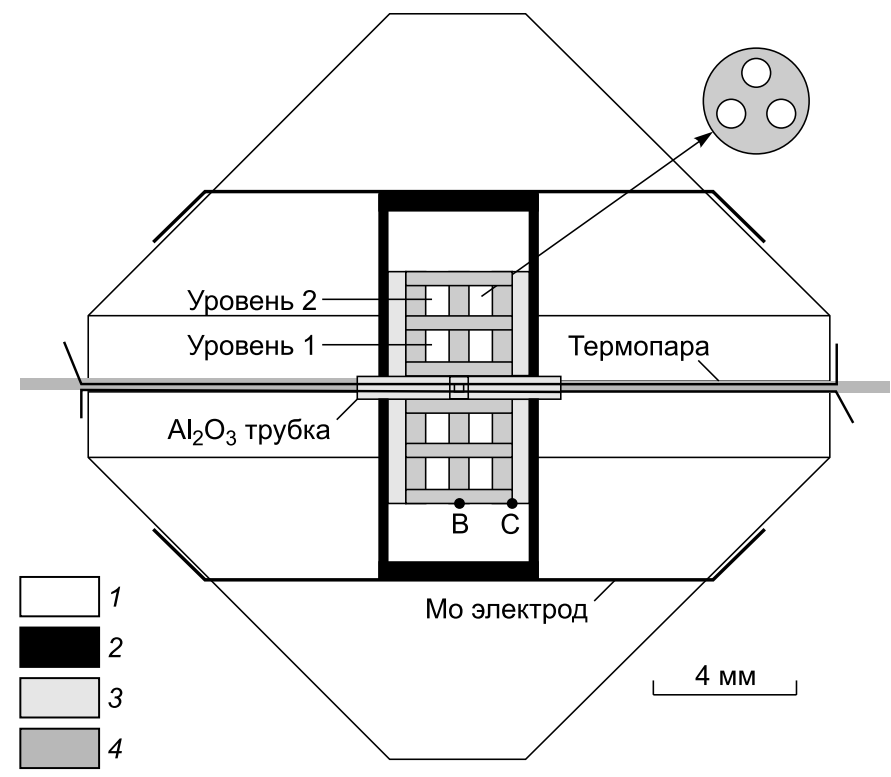
$\mathrm{CaGeO}_{3}$ [Ono et al., 2011]. Использование аналогичной ячейки в in situ рентгенографических экспериментах с применением шкалы $\mathrm{Au}$ и $\mathrm{MgO}$ [Соколова и др., 2013] на линии синхротронного излучения BL04B1 ускорителя «Spring-8», Япония, показало, что отклонение давления от желаемой величины в процессе нагрева до 1200-1800 К не превышает \pm 0.5 ГПа [Shatskiy et al., 2013]. Методические детали калибровки по давлению приведены в работах [Shatskiy et al., 2011, 2013; Litasov et al., 2013b].

В качестве исходных веществ использовали порошки $\mathrm{CaCO}_{3}(99.9$ \%, Wako Pure Chem. Ind., Ltd., Япония) и $\mathrm{Fe}(99.9 \%$, Rare Metallic Co. Ltd., Япония). Капсулы изготавливали из BN, MgO и железа чистотой не менее $99.9 \%$. Перед опытом образцы просушивали при 420 К в течение 2-3 ч в вакуумном эксикаторе.

После экспериментов образцы размещали в шашках, заполненных маловязкой эпоксидной смолой. Шашки полировали в масле с помощью наждачной бумаги зернистостью 800, 1000 и 1500 меш и алмазных паст зернистостью 3 и 1 мкм. Для удаления масла и паст с поверхности образцов использовали бензин. Отполированные образцы напыляли углеродом или хромом и исследовали на сканирующем электронном микроскопе Tescan-MIRA 3 LMU с энергодисперсионной приставкой для количественного анализа Inca-Energy в ИГМ СО РАН (г. Новосибирск). Образцы анализировали при ускоряющем напряжении 20 кВ и токе 1 нА. ЭДС измерения калибровали с помощью стандартов с известным составом. Для анализа карбидов и металла использовались стандартные образцы $\mathrm{Fe}_{3} \mathrm{C}$ и $\mathrm{Fe}_{7} \mathrm{C}_{3}$.

\section{РЕЗУЛЬТАТЫ ЭКСПЕРИМЕНТОВ}

\section{Эксперименты в железной капсуле}

Между Са-карбонатом и железом при 6 ГПа наблюдался ряд твердофазных реакций, а также реакций, сопровождающихся плавлением (табл. 1). Эксперименты в железной капсуле проводили со следующими реагентами: (1) $\mathrm{CaCO}_{3}$, (2) $\mathrm{CaCO}_{3}+\mathrm{Fe}$ и (3) $\mathrm{CaCO}_{3}+2 \mathrm{Fe}$ (мол. \%). Анализ полученных образцов показал, что продукты реакции отличаются незначительно для всех опытов в диапазоне температур $1273-1673 \mathrm{~K}$. В процессе взаимодействия $\mathrm{CaCO}_{3}-\mathrm{Fe}$ образуется Са-вюстит и карбид $\mathrm{Fe}_{3} \mathrm{C}$. Карбонат во всех случаях представлен арагонитом. Основываясь на полученных результатах, уравнение ОВ реакции можно записать следующим образом:

$$
\mathrm{CaCO}_{3}+5 \mathrm{Fe}=3\left(\mathrm{Fe}_{0.67} \mathrm{Ca}_{0.33}\right) \mathrm{O}+\mathrm{Fe}_{3} \mathrm{C} .
$$

Продукты реакции образуют реакционную зону, возникающую на контакте карбоната с железом (рис. $2, a$ ). Изменение толщины этой зоны в зависимости от экспериментальных условий является важнейшим параметром в случае твердофазного взаимодействия, позволяющим определить механизм протекания реакции, а также рассчитать кинетические параметры, которые предполагается получить в дальнейших экспериментах с разрешением по времени опыта. Толщина реакционной зоны увеличивается от 15 до 120 мкм в зависимости от длительности и температуры (см. табл. 1). В самой железной капсуле установлены следы реакционного взаимодействия. Вблизи контакта с $\mathrm{CaCO}_{3}$ в железе отмечается зона толщиной 50-100 мкм, в ней можно обнаружить округлые включения вюстита (см. рис. 2). Этот вюстит содержит небольшое количество примесей $\mathrm{Cr}$, Al и $\mathrm{Mn}(<0.3$ мас. \%). Происхождение 
Таблица 1 .

Результаты экспериментов

\begin{tabular}{|c|c|c|c|c|c|c|}
\hline Номер образца & Реагенты, мол. \% & Капсула & $T, \mathrm{~K}$ & Время, мин & Продукты реакции & $\begin{array}{c}\text { Реакционная } \\
\text { зона, мкм }\end{array}$ \\
\hline T1919 & 1) $\mathrm{CaCO}_{3}$ & $\mathrm{Fe}$ & $1273(10)$ & 720 & $\mathrm{CaCO}_{3}, \mathrm{Ca}-\mathrm{Wu}$ & $12(3)$ \\
\hline ES258 & $\begin{array}{l}\text { 1) } \mathrm{CaCO}_{3} \\
\text { 2) } \mathrm{CaCO}_{3}+\mathrm{Fe} \\
\text { 3) } \mathrm{CaCO}_{3}+2 \mathrm{Fe}\end{array}$ & $\mathrm{Fe}$ & $1473(10)$ & 10 & $\mathrm{CaCO}_{3}, \mathrm{Ca}-\mathrm{Wu}, \mathrm{Fe}_{3} \mathrm{C}$ & $\begin{array}{l}40(7) \\
45(5) \\
45(5) \\
\end{array}$ \\
\hline $\mathrm{T} 1918$ & 1) $\mathrm{CaCO}_{3}$ & $\mathrm{Fe}$ & $1473(10)$ & 120 & $\mathrm{CaCO}_{3}, \mathrm{Ca}-\mathrm{Wu}, \mathrm{Fe}_{3} \mathrm{C}$ & $72(6)$ \\
\hline T1877 & $\begin{array}{l}\text { 2) } \mathrm{CaCO}_{3}+\mathrm{Fe} \\
\text { 3) } \mathrm{CaCO}_{3}+2 \mathrm{Fe}\end{array}$ & $\mathrm{Fe}$ & $1473(10)$ & 200 & $\begin{array}{l}\mathrm{CaCO}_{3}, \mathrm{Ca}-\mathrm{Wu}, \mathrm{Fe}_{3} \mathrm{C} \\
\mathrm{Ca}-\mathrm{Wu}, \mathrm{Fe}_{3} \mathrm{C}, \mathrm{Lm}\end{array}$ & $120(10)$ \\
\hline $\mathrm{T} 1868$ & $\begin{array}{l}\text { 1) } \mathrm{CaCO}_{3} \\
\text { 2) } \mathrm{CaCO}_{3}+\mathrm{Fe} \\
\text { 3) } \mathrm{CaCO}_{3}+2 \mathrm{Fe}\end{array}$ & $\mathrm{Fe}$ & $1673(20)$ & 20 & $\mathrm{CaCO}_{3}, \mathrm{Ca}-\mathrm{Wu}, \mathrm{Fe}_{7} \mathrm{C}_{3}$ & $\begin{array}{c}60(10) \\
140(20) \\
210(20) \\
\end{array}$ \\
\hline T1920 & 3) $\mathrm{CaCO}_{3}+2 \mathrm{Fe}$ & $\mathrm{BN}$ & $1473(10)$ & 480 & $\mathrm{CaCO}_{3}, \mathrm{Ca}-\mathrm{Wu}, \mathrm{Fe}_{3} \mathrm{C}, \mathrm{CL}, \mathrm{Gr}$ & - \\
\hline $\mathrm{T} 1889$ & $\begin{array}{l}\text { 2) } \mathrm{CaCO}_{3}+\mathrm{Fe} \\
\text { 3) } \mathrm{CaCO}_{3}+2 \mathrm{Fe}\end{array}$ & $\mathrm{BN}$ & $1673(10)$ & 180 & $\mathrm{CaCO}_{3}, \mathrm{Ca}-\mathrm{Wu}, \mathrm{CL}, \mathrm{ML}, \mathrm{Gr}$ & - \\
\hline $\mathrm{T} 1876$ & $\begin{array}{l}\text { 2) } \mathrm{CaCO}_{3}+\mathrm{Fe} \\
\text { 3) } \mathrm{CaCO}_{3}+2 \mathrm{Fe}\end{array}$ & $\mathrm{BN}$ & $1873(20)$ & 40 & $\mathrm{CL}, \mathrm{ML}, \mathrm{Gr}$ & - \\
\hline $\mathrm{T} 1870$ & $\begin{array}{l}\text { 2) } \mathrm{CaCO}_{3}+\mathrm{Fe} \\
\text { 3) } \mathrm{CaCO}_{3}+2 \mathrm{Fe}\end{array}$ & $\mathrm{MgO}$ & $1673(10)$ & 180 & Cmw, CL, ML, Gr & - \\
\hline $\mathrm{T} 1871$ & $\begin{array}{l}\text { 2) } \mathrm{CaCO}_{3}+\mathrm{Fe} \\
\text { 3) } \mathrm{CaCO}_{3}+2 \mathrm{Fe}\end{array}$ & $\mathrm{MgO}$ & $1873(40)$ & 30 & $\mathrm{Cmw}, \mathrm{CL}, \mathrm{Gr}$ & - \\
\hline
\end{tabular}

При мечан ие. Давление составляло 6 ГПа во всех опытах. Ca-Wu $-(\mathrm{Ca}, \mathrm{Fe}) \mathrm{O}-$ вюстит, $\mathrm{Lm}-$ известь, $\mathrm{CaO}, \mathrm{CL}-$ карбонатный расплав, $\mathrm{Gr}$ - графит, $\mathrm{ML}$ — металлический расплав, $\mathrm{Cmw}$ - $(\mathrm{Ca}, \mathrm{Mg}, \mathrm{Fe}) \mathrm{O}-$ вюстит. Ширина реакционной зоны не указана для образцов, в которых наблюдалось полное замещение реагентов продуктами реакции. Прочерк - не измерялось. В скобках показана величина максимальной ошибки.

включений можно объяснить миграцией окисленного C-O-содержащего флюида в сторону Fe с дальнейшим реакционным взаимодействием:

$$
(1-x) \mathrm{Fe}+1 / 2 \mathrm{O}_{2}=\mathrm{Fe}_{(1-x)} \mathrm{O}
$$

или

$$
4 \mathrm{Fe}+\mathrm{CO}=\mathrm{Fe}_{3} \mathrm{C}+\mathrm{FeO} .
$$

Привнос $\mathrm{CO}$ или $\mathrm{CO}_{2}$ в железо, а значит и реакция (3), являются наиболее вероятными причинами образования вюстита в железе, несмотря на то, что вокруг включений не обнаружено выделений карбида. Реакционная зона в образцах с большим количеством железа (реагенты 2 и 3) была шире, чем в чистом $\mathrm{CaCO}_{3}$. Однако в коротких опытах (обр. ES258) эта величина фактически одинаковая для всех трех составов. В эксперименте, который проводился при температуре $1473 \mathrm{~K}$ в течение 200 мин, мы наблюдали полное замещение карбоната с образованием $(\mathrm{Ca}, \mathrm{Fe}) \mathrm{O}, \mathrm{Fe}_{3} \mathrm{C}$ и незначительного количества $\mathrm{Fe}-$ содержащей извести, $\mathrm{CaO}$.

Составы фаз, полученные с использованием энергодисперсионного анализа, приведены в табл. 2. Карбид железа представлен стехиометричным $\mathrm{Fe}_{3} \mathrm{C}$ с небольшими примесями $\mathrm{Ca}(0.4-0.8$ мас. \%) и $\mathrm{O}$, которые могут быть связаны с погрешностью измерений.

Поскольку в системе карбонат-железо при 3-5 ГПа и 1600-1700 К были обнаружены кальциевые ферриты [Чепуров и др., 2011], важное значение имеет идентификация структуры образующихся в эксперименте кальцийсодержащих фаз. Согласно данным анализа продуктов исследуемой реакции методом микрофокусной рентгеновской дифрактометрии, структура оксидной фазы с Сa и Fe соответствует вюститу. Концентрация кальция в вюстите составляет 20-25 мас. \% и практически не зависит от общего содержания железа в системе (одинакова для реагентов 2 и 3 , см. табл. 2).

В экспериментальной капсуле существует градиент ОВ условий. Точные значения для ассоциации $\mathrm{Fe}-\mathrm{Ca}$ - вюстит рассчитать достаточно сложно из-за отсутствия термодинамических данных для Са-вюстита, но по аналогии с ассоциацией Fe-магнезиовюстит [Takahashi et al., 2013] можно предположить, что на границе железа с карбонатом в реакционной зоне $f_{\mathrm{O}_{2}}$ примерно соответствует значениям $\Delta \lg f_{\mathrm{O}_{2}}$ (IW) от 0 до -0.5 лог. ед., а устойчивости карбоната или карбонатитового расплава соответствует $\Delta \lg f_{\mathrm{O}_{2}}(\mathrm{IW})=2.7-3.2$ лог. ед. Последние значения рассчитаны по методу, предложенному в работе 

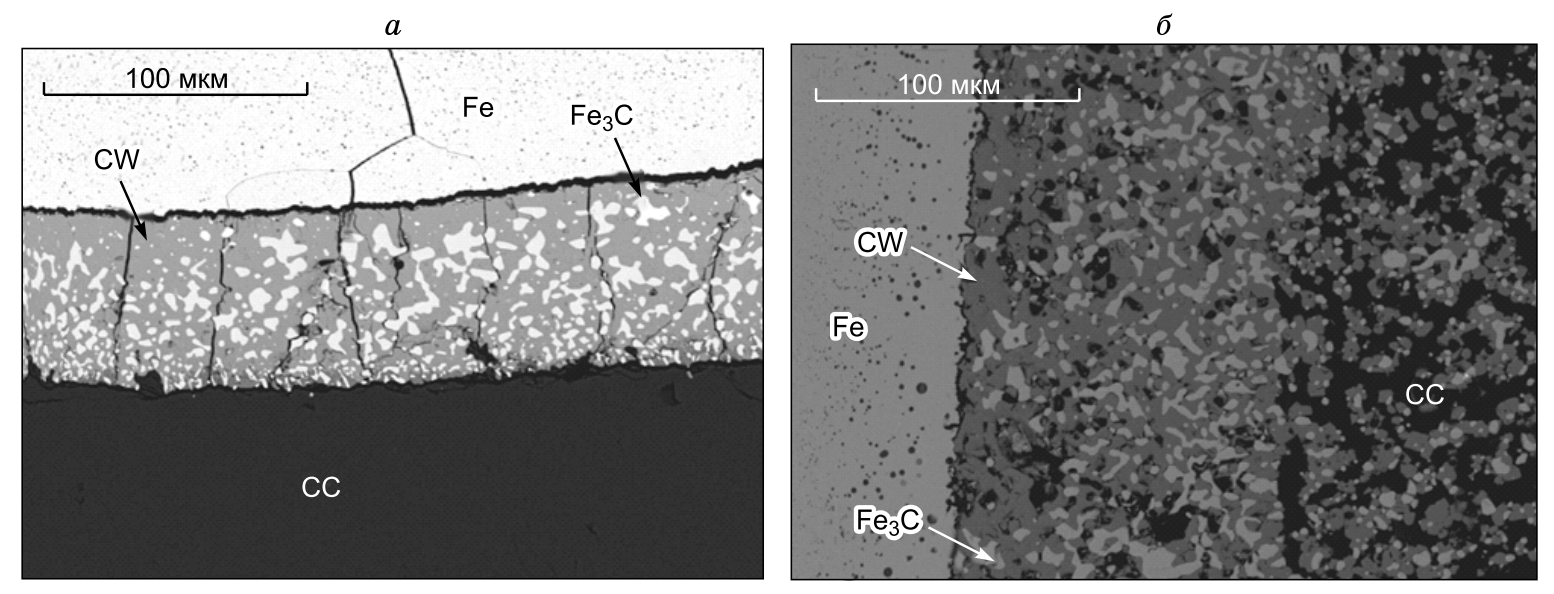

Рис. 2. Изображение экспериментальных образцов из железной капсулы в обратнорассеянных электронах.

$a$ - обр. Т1918, $1473 \mathrm{~K}, 120$ мин; б - обр. Т1877, $1473 \mathrm{~K}, 200$ мин. СС - $\mathrm{CaCO}_{3}, \mathrm{CW}$ - (Ca,Fе)О. Отчетливо видны включения вюстита в металле.

[Stagno, Frost, 2010]. При этом металлическое железо (или расплав) устойчиво вместе с карбонатитовым расплавом при этих условиях и на $2-3$ лог. ед. выше буфера IW. Примерно такие же значения $f_{\mathrm{O} 2}$ характерны и для реакционных ассоциаций в капсулах $\mathrm{BN}$ и $\mathrm{MgO}$, если в образце присутствуют все реагенты (Fe, вюстит, карбонатитовый расплав).

\section{Эксперименты в капсуле BN}

Использование капсулы из нитрида бора в незначительной степени влияет на результаты экспериментов. На границе с капсулой наблюдается образование небольшого количества удлиненных гексагональных кристаллов BN, а также зерен нитридов Сa и Fe. Взаимодействие железа и карбоната кальция начинается в центральной части образца, где $\mathrm{CaCO}_{3}$ полностью плавится и частично восстанавливается в присутствии металлической фазы с образованием кристаллов $(\mathrm{Ca}, \mathrm{Fe}) \mathrm{O}$ и карбида. В то же время на периферии $\mathrm{CaCO}_{3}$ в ассоциации с графитом сохраняется неизмененным (рис. 3).

При 1473 К Fе и карбид Fе остаются в кристаллической форме, в то время как при $1873 \mathrm{~K}$ установлено их плавление. Определение точной температуры плавления затруднено из-за небольших размеров зерен $\mathrm{Fe}_{3} \mathrm{C}$ и железа при $1673 \mathrm{~K}$. Частицы расплава и зерна карбида имеют округлые формы во всех экспериментах при 1473$1873 \mathrm{~K}$ и с трудом отличимы друг от друга. Однако жидкая фаза, вероятно,

\section{Рис. 3. Изображение эксперимен- тальных образцов в капсуле из нитрида бора в обратнорассеянных электронах.}

а, б - обр. Т1889, $1673 \mathrm{~K}, 180$ мин; в, гобр. Т1920, $1473 \mathrm{~K}, 480$ мин. Gr - графит, ML - металлический расплав, CL - карбонатный расплав. Остальные усл. обозн. см. на рис. 2.

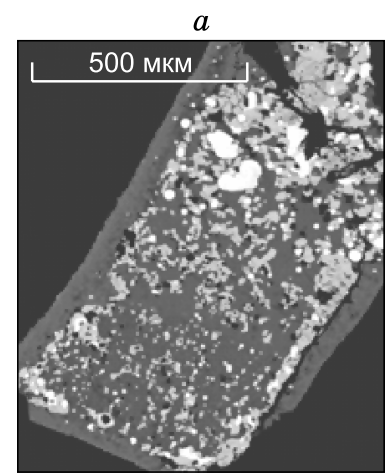

B

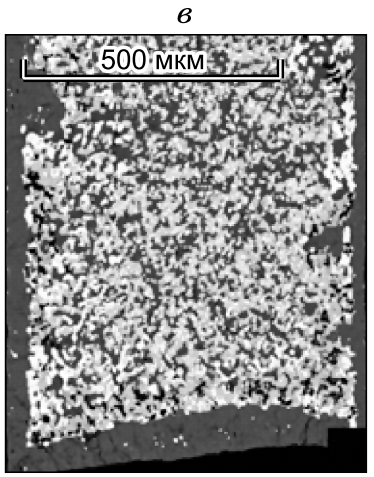

$\sigma$

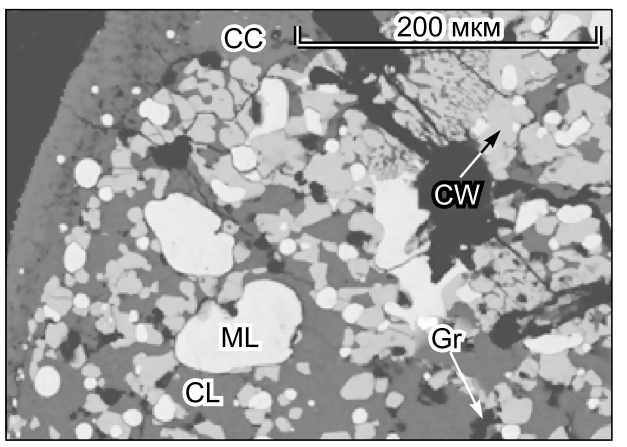

2

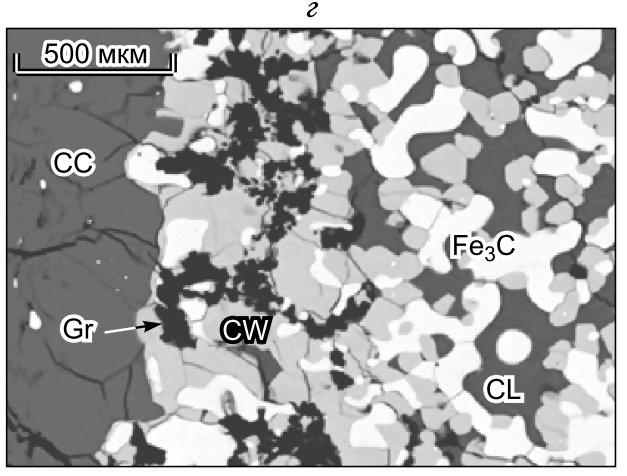




\begin{tabular}{|c|c|c|c|c|c|c|}
\hline Фаза & $\mathrm{Ca}$ & $\mathrm{Mg}$ & $\mathrm{Fe}$ & $\mathrm{C}$ & $\mathrm{O}$ & Сумма \\
\hline \multicolumn{7}{|c|}{ Обр. Т1919 } \\
\hline $\mathrm{CaCO}_{3}$ & 40.1 & & - & 11.8 & 48.4 & 100.3 \\
\hline $\mathrm{Ca}-\mathrm{Wu}$ & 17.7 & & 58.6 & 一 & 23.6 & 99.9 \\
\hline Fe-rim* & - & & 98.2 & 0.23 & 0.79 & 99.2 \\
\hline $\mathrm{Fe}$ & - & & 100.4 & - & - & 100.4 \\
\hline \multicolumn{7}{|c|}{ Обр. Т1918 } \\
\hline $\mathrm{CaCO}_{3}$ & 39.7 & & - & 11.9 & 48.2 & 99.8 \\
\hline $\mathrm{Ca}-\mathrm{Wu}$ & 19.4 & & 55.2 & - & 25.1 & 99.7 \\
\hline $\mathrm{Fe}_{3} \mathrm{C}$ & 0.55 & & 91.7 & 6.1 & 0.79 & 99.2 \\
\hline $\mathrm{Fe}$ & - & & 100.9 & - & - & 100.9 \\
\hline \multicolumn{7}{|c|}{ Обр. Т1877 (2) } \\
\hline $\mathrm{CaCO}_{3}$ & 40.1 & & 0.85 & 11.2 & 48.1 & 100.3 \\
\hline $\mathrm{Ca}-\mathrm{Wu}$ & 23.9 & & 51.4 & - & 24.2 & 99.5 \\
\hline $\mathrm{Fe}_{3} \mathrm{C}$ & 0.71 & & 93.0 & 6.2 & - & 99.9 \\
\hline \multicolumn{7}{|c|}{ Обр. Т1877 (3) } \\
\hline $\mathrm{Ca}-\mathrm{Wu}$ & 24.3 & & 50.6 & - & 24.4 & 99.3 \\
\hline $\mathrm{Fe}_{3} \mathrm{C}$ & 0.54 & & 92.1 & 6.5 & 0.73 & 99.9 \\
\hline $\mathrm{Lm}$ & 56.9 & & 15.1 & - & 27.8 & 99.8 \\
\hline \multicolumn{7}{|c|}{ Обр. Т1868 (2) } \\
\hline $\mathrm{CaCO}_{3}$ & 39.1 & & 1.15 & 11.6 & 46.9 & 98.8 \\
\hline $\mathrm{Ca}-\mathrm{Wu}$ & 20.6 & & 54.7 & - & 25.2 & 100.5 \\
\hline $\mathrm{Fe}_{7} \mathrm{C}_{3}$ & 0.55 & & 92.4 & 7.9 & - & 100.3 \\
\hline \multicolumn{7}{|c|}{ Обр. Т1920 } \\
\hline $\mathrm{CaCO}_{3}$ & 40.0 & & 一 & 12.1 & 47.6 & 99.7 \\
\hline $\mathrm{Ca}-W u$ & 5.2 & & 72.2 & - & 22.7 & 100.1 \\
\hline CL & 39.7 & & 1.0 & 10.6 & 47.4 & 98.7 \\
\hline $\mathrm{Fe}_{3} \mathrm{C}$ & 0.77 & & 91.5 & 6.8 & 0.40 & 99.5 \\
\hline \multicolumn{7}{|c|}{ Обр. Т1889 (2) } \\
\hline $\mathrm{CaCO}_{3}$ & 40.2 & & 0.45 & 11.8 & 47.6 & 100.1 \\
\hline $\mathrm{Ca}-W u$ & 6.3 & & 70.5 & - & 22.7 & 99.5 \\
\hline CL & 38.9 & & 0.8 & 10.7 & 46.9 & 97.3 \\
\hline ML & 0.32 & & 93.7 & 5.7 & 0.49 & 100.2 \\
\hline \multicolumn{7}{|c|}{ Обр. Т1876 (3) } \\
\hline $\mathrm{CL}$ & 36.0 & & 5.2 & 8.9 & 47.3 & 97.4 \\
\hline ML & 0.51 & & 92.6 & 5.4 & 0.33 & 98.8 \\
\hline \multicolumn{7}{|c|}{ Обр. Т1870 (2) } \\
\hline $\mathrm{Cmw}$ & 7.8 & 17.2 & 44.7 & - & 30.1 & 99.8 \\
\hline $\mathrm{CL}$ & 41.7 & & 0.65 & 10.9 & 43.9 & 97.2 \\
\hline ML & 0.45 & & 91.5 & 5.6 & - & 97.6 \\
\hline \multicolumn{7}{|c|}{ Обр. Т1871 (2) } \\
\hline $\mathrm{Cmw}$ & 10.4 & 17.1 & 43.7 & - & 28.1 & 99.3 \\
\hline CL & 40.2 & 0.10 & 0.43 & 9.6 & 46.3 & 96.6 \\
\hline
\end{tabular}

Примечание. Точность анализа углерода в карбиде составляет $15 \%$, в карбонате $11 \%$. Усл. обозн. см. табл. 1. Fe-rim* — состав, полученный в краевой реакционной зоне. В скобках указан номер реагента (см. табл. 1).

содержит немного меньше углерода (4-6 мас. \%), чем кристаллический карбид (6.7 мас. \%), что согласуется с фазовой диаграммой Fe-C при 6 ГПа [Lord et al., 2009].

Са-вюстит содержит 5-6 мас. \% Са и полностью исчезает при 1873 К. Карбонатитовый расплав представлен практически чистым Са-карбонатом при $1473-1673$ K, но может содержать $0.8-1.0$ мас. \% Fe. При 1873 K концентрация железа достигает 5.2 мас. \%. Несмотря на то, что количественный ЭДС 


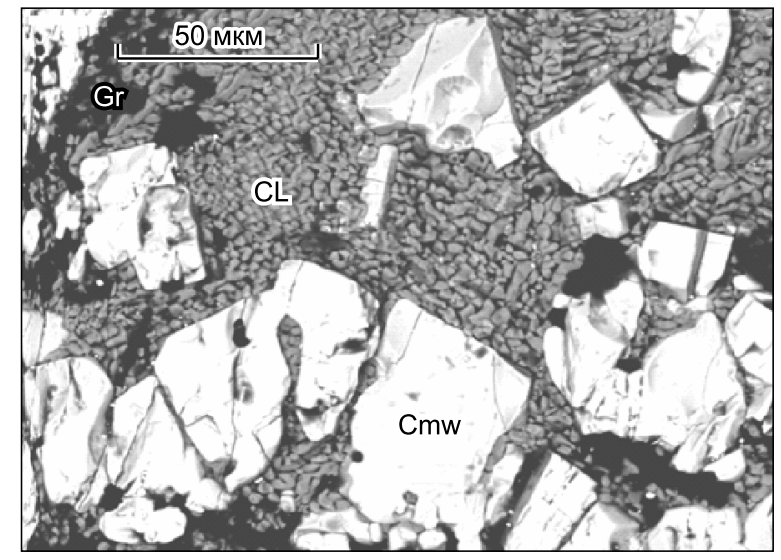

$\sigma$

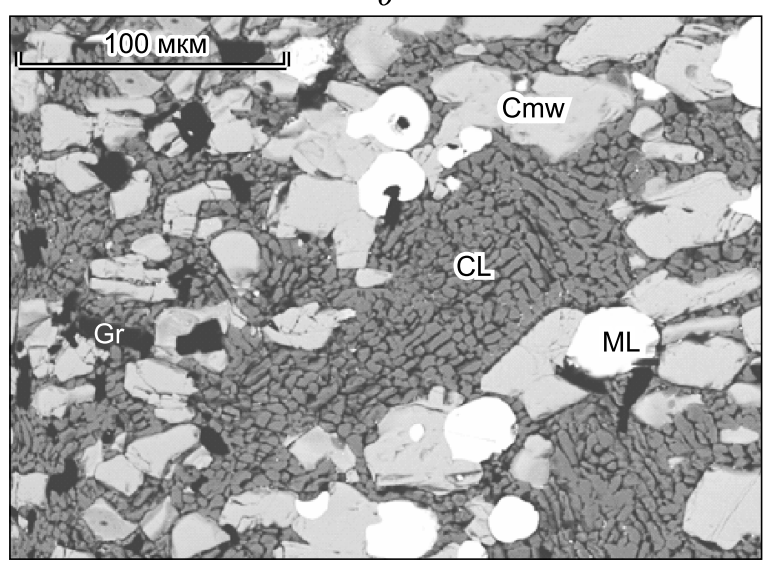

Рис. 4. Изображение экспериментальных образцов в капсуле из MgO в обратнорассеянных электронах.

$a$ - обр. Т1871, 1873 K, 30 мин; б - обр. Т1870, 1673 K, 180 мин. Cmw - (Ca,Mg,Fe)О. Остальные усл. обозн. см. на рис. 3.

анализ С и О в фазах, одновременно содержащих эти элементы, затруднителен, оценив результаты всех анализов, можно сделать вывод, что продукты закалки карбонатного расплава обеднены кислородом и углеродом и обогащены кальцием относительно стехиометрии $\mathrm{CaCO}_{3}$. Этот дефицит важен для расчета баланса масс продуктов реакции, в которых представлен кальциевый вюстит. Пики азота или бора не были обнаружены на ЭДС спектрах карбонатного расплава, что указывает на незначительную контаминацию материалом капсулы. Нужно подчеркнуть, что температура плавления карбоната в исследуемой системе составляет $1473 \mathrm{~K}$, что значительно ниже температуры ликвидуса $\mathrm{CaCO}_{3}$.

\section{Эксперименты в капсуле MgO}

Продукты реакции кальцита с железом при $1673 \mathrm{~K}$ в капсуле из $\mathrm{MgO}$ представлены $(\mathrm{Ca}, \mathrm{Mg}, \mathrm{Fe}) \mathrm{O}$, расплавом $\mathrm{CaCO}_{3}$, металлическим расплавом и графитом (рис. 4). При $1873 \mathrm{~K}$ металлическая жидкость отсутствует. (Ca, $\mathrm{Mg}, \mathrm{Fe}) \mathrm{O}$ со структурой вюстита содержит значительные количества $\mathrm{Mg}$ (см. табл. 2), в то же время карбонатный расплав фактически полностью состоит из $\mathrm{CaCO}_{3}$ с небольшими примесями $\mathrm{Fe}=0.4-0.7$ мас. \%. Проанализированный состав продуктов реакции не зависит от первоначальной концентрации железа в реагентах 2 и 3.

\section{ОБСУЖДЕНИЕ РЕЗУЛЬТАТОВ}

Детальное исследование реакции железо-карбонат является важной задачей для понимания процессов на границе субдуцирующей плиты и мантии. Существует лишь небольшое количество публикаций, где рассмотрены подобные системы. Термодинамические расчеты для реакции $\mathrm{Fe}+\mathrm{MgCO}_{3}$ были осуществлены в работе [Scott et al., 2001]. Согласно полученным результатам, ассоциация $\mathrm{Fe}_{3} \mathrm{C}+$ магнезиовюстит будет замещать железо-магнезит в силу большей стабильности в условиях верхней и нижней мантии. Подобные выводы также подтверждают теоретические исследования на основании расчета энтальпии образования из первых принципов при 0 K [Oganov et al., 2008] и недавние эксперименты [Palyanov et al., 2013; Martirosyan et al., 2015].

В многопуансонных прессах при 14-23 ГПа были проведены эксперименты с карбонатизированным перидотитом, представляющим собой более сложную многокомпонентную систему. Наблюдалось восстановление магнезита, согласно реакции [Rohrbach, Schmidt, 2011]:

$$
\mathrm{MgCO}_{3}+2(\mathrm{Fe}, \mathrm{Ni})=3(\mathrm{Fe}, \mathrm{Ni}, \mathrm{Mg}) \mathrm{O}+\mathrm{C} .
$$

Образующийся в процессе взаимодействия магнезита с металлической фазой вюстит $(\mathrm{Fe}, \mathrm{Ni}, \mathrm{Mg}) \mathrm{O}$ может кристаллизоваться в собственную фазу либо растворяться в структуре окружающих силикатов. Важным вопросом в экспериментах [Rohrbach, Schmidt, 2011] является кристаллизация графита или алмаза в металлической капсуле. Поскольку более стабильным соединением в таких условиях является карбид, можно предположить, что металлическая капсула и полученные продукты реакции (4) неравновесны. Очевидно, что в зависимости от соотношения $\mathrm{Fe}-\mathrm{C}$ в системе и $P$-T-условий [Dasgupta, Hirs- 
chmann, 2010] некоторое количество углерода будет растворяться в материале капсулы, приводя к образованию $\mathrm{Fe}_{3} \mathrm{C}$ или $\mathrm{Fe}_{7} \mathrm{C}_{3}$ [Palyanov et al., 2013].

Система $\mathrm{CaCO}_{3}+\mathrm{Fe}$ изучалась экспериментально при 5.5 ГПа и $1573-1673 \mathrm{~K}$ [Чепуров и др., 2011]. Авторы наблюдали образование ферритов кальция $\left(\mathrm{CaFeO}_{2}, \mathrm{CaFeO}_{3}, \mathrm{CaFe}_{4} \mathrm{O}_{7}\right)$ и $\mathrm{CaCO}_{3}$, но не отмечали карбидов или расплавов, что не согласуется с нашими результатами. Структуры соединений кальция и железа, определенные нами методом микрофокусной дифрактометрии, соответствуют вюститу, а не ферритам.

Система $\mathrm{CaCO}_{3}+\mathrm{Fe}$ изучалась в присутствии воды в алмазных наковальнях в диапазоне давлений 5-11 ГПа и при температурах 773-1773 K [Scott et al., 2004]. В экспериментах наблюдалось образование метана согласно реакции:

$$
\mathrm{CaCO}_{3}+8 \mathrm{FeO}+2 \mathrm{H}_{2} \mathrm{O}=4 \mathrm{Fe}_{2} \mathrm{O}_{3}+\mathrm{CH}_{4}+\mathrm{CaO} .
$$

Кроме систем $\mathrm{CaCO}_{3}+\mathrm{Fe}, \mathrm{MgCO}_{3}+\mathrm{Fe}$ была детально исследована система $\mathrm{Fe}-\left(\mathrm{Mg}_{0.9} \mathrm{Ca}_{0.1}\right) \mathrm{CO}_{3}$ при 6.5-7.5 ГПа и 1273-1923 К в платиновых ампулах [Palyanov et al., 2013]. Ocoбое внимание было уделено кристаллизации алмаза из карбонатного и металлического расплавов в результате ОВ реакций. Реакция инициируется разностью потенциалов между окисленным богатым кальцием карбонатным и восстановленным железо-углеродным расплавами.

$\mathrm{B}$ нашем исследовании детально изучено взаимодействие металлического железа и $\mathrm{CaCO}_{3}$ при 6 ГПа, которое описывает в первом приближении механизм процесса, происходящего в погружающейся субдукционной плите на контакте с восстановленными мантийными породами. Данная ОВ реакция протекает с образованием кальциевого вюстита или карбонатитового расплава, которые кристаллизуются совместно с карбидом $\mathrm{Fe}_{3} \mathrm{C}$ или металлическим расплавом. Обобщая все результаты, полученные при анализе образцов, можно выделить три характерные ассоциации продуктов экспериментов, образующихся в зависимости от температуры:

$$
\begin{gathered}
\text { при } 1273-1473 \mathrm{~K}: \mathrm{CaCO}_{3}+5 \mathrm{Fe}=3\left(\mathrm{Fe}_{0.66} \mathrm{Ca}_{0.33}\right) \mathrm{O}+\mathrm{Fe}_{3} \mathrm{C}, \\
\text { при } 1473-1673 \mathrm{~K}: \mathrm{CaCO}_{3}+11 \mathrm{Fe}=8 \mathrm{CaCO}_{2.5}(\mathrm{~L})+10\left(\mathrm{Fe}_{0.8} \mathrm{Ca}_{0.2}\right) \mathrm{O}+\mathrm{Fe}_{3} \mathrm{C}(\mathrm{L})+\mathrm{C}, \\
\text { при } 1873 \mathrm{~K}: 5 \mathrm{CaCO}_{3}+4 \mathrm{Fe}=4 \mathrm{CaCO}_{2.5}(\mathrm{~L})+5\left(\mathrm{Fe}_{0.8} \mathrm{Ca}_{0.2}\right) \mathrm{O}+\mathrm{C} .
\end{gathered}
$$

Следует отметить, что в отличие от работы [Palyanov et al., 2013] давление было недостаточным для формирования алмаза. Несмотря на то, что эксперименты проводились в поле стабильности алмаза (рис. 5), каталитического эффекта металлического расплава или карбонатитового расплава было недостаточно для перехода графит-алмаз. Минимальные давления и температуры, где алмаз (совместно с графитом) кристаллизовался из щелочноземельного карбонатитового расплава, составляли 6.5 ГПа и 1623 K [Palyanov et al., 2013]. Соответственно, эти катализаторы являются более худшими по сравнению со щелочными карбонатитовыми расплавами и $\mathrm{H}_{2} \mathrm{O}-\mathrm{CO}_{2}$-флюидом, где алмаз кристаллизуется при 5.7 ГПа и 1423 К [Sokol et al., 2001; Pal'yanov et al., 2002; Шацкий и др., 2002]. Длительности наших опытов были несколько меньше, чем в работе [Palyanov et al., 2013], но в целом сопоставимы. В метал-

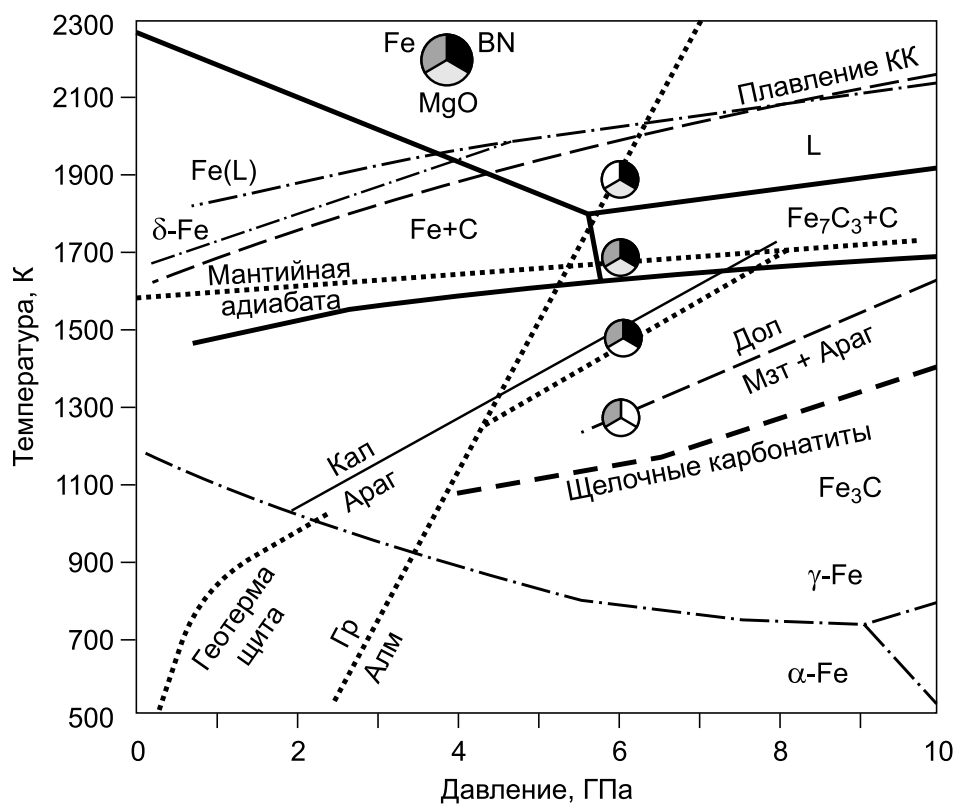

\section{Рис. 5. P-T-параметры экспериментов в системе железо-Са-карбонат.}

На диаграмме для сравнения приведены необходимые фазовые равновесия и характерные мантийные $P$-T-профили. Символы показывают материал капсулы (на сноске). Штрихпунктирные линии соответствуют фазовой диаграмме Fe [Komabayashi, Fei, 2010], жирные линии - фазовой диаграмме $\mathrm{Fe}$ - C [Nakajima et al., 2009]. Показана линия плавления карбоната кальция (КК) [Irving, Wyllie, 1975; Suito et al., 2001]. Переход кальцит-арагонит (Кал-Араг) отмечен согласно [Suito et al., 2001]. Реакция магнезит + арагонит $=$ доломит $($ Мзт + Араг = Дол) показана по данным [Shirasaka et al., 2002]. Гр-Алм - переход графит-алмаз, по [Kennedy, Kennedy, 1976]. Мантийная адиабата и геотерма кратонов взята из [Литасов, 2011]. Солидус щелочных карбонатитов отмечен на диаграмме на основании данных работы [Litasov et al., 2013b]. 
лических расплавах алмаз кристаллизуется при температурах не менее 1773 К и 6 ГПа [Жимулев и др., 2012], а в металл-сульфидных - при 1573 К и 5.5 ГПа [Чепуров и др., 1998, 2009].

Коэффициенты в реакциях (7) и (8) расставлены условно, поскольку карбонатный расплав и оксид могут слегка отличаться от формулы, указанной выше. Во всех реакциях наблюдается значительное поглощение железа в процессе взаимодействия с твердым карбонатом и карбонатитовым расплавом. Это означает, что в реальной мантии карбонатитовый расплав способен переработать (окислить) большой объем мантии, содержащей железо или другие восстановленные компоненты. В модели «карбонатитового диапира» [Litasov et al., 2013b] первый же карбонатитовый диапир (0.5-1 км), способный отделиться от субдукционной плиты в переходном слое, может полностью окислить вышележащие мантийные толщи на глубинах от 550 до 200 км, потеряв лишь 30 \% углерода, который перейдет в восстановленные формы, например, в алмаз.

Плавление кальциевого карбоната в присутствии Fе при давлении 6 ГПа происходит в интервале температур 1473-1573 K, что соответствует условиям, при которых арагонит плавится в сложных карбонатсодержащих системах [Shirasaka, Takahashi, 2003; Kiseeva et al., 2012, 2013; Litasov et al., 2013b], но значительно ниже температуры ликвидуса в системе $\mathrm{CaCO}_{3}$ (см. рис. 5). Хотя в восстановительных условиях наблюдается небольшой дефицит кислорода, в целом состав карбонатного расплава не зависит от присутствия железа и представлен чистым $\mathrm{CaCO}_{3}$, сосуществующим с жидким металлическим $\mathrm{Fe}$ или кальциевым вюститом при температурах мантийной адиабаты. В субдукционных обстановках [Syracuse et al., 2010] (см. рис. 5) карбонат кальция остается твердым в присутствии железа при 6 ГПа. Однако при непосредственном контакте они всегда будут вступать в реакцию, согласно уравнению (6), замещаясь на стабильную мантийную ассоциацию вюстит-карбид (оксидная часть может входить в состав силикатов).

Кристаллизация железа и практически чистого Са-карбонатитового расплава в экспериментальных образцах объясняет совместное нахождение подобных включений в алмазах как литосферных, так и сверхглубинных. В разных ассоциациях железо, вюстит, карбонаты кальция, а в некоторых случаях и карбид железа обнаружены в алмазах Якутской провинции [Соболев и др., 1981; Logvinova et al., 2008; Логвинова и др., 2011], а также, например, в сверхглубинных алмазах Бразилии вместе с нижнемантийными ассоциациями [Hayman et al., 2005; Kaminsky, Wirth, 2011; Kaminsky, 2012]. В этом случае карбонаты кальция могут являться закалочными кристаллами карбонатитового расплава, а железо или карбиды - закалочными фазами металлической жидкости или представляют твердофазные включения, если образовались ниже температуры плавления.

Наиболее значимые вопросы, на которые могли бы ответить исследования системы Fe-карбонат, связаны с процессами на границе ядро-мантия. Однако наши результаты не могут быть напрямую экстраполированы до таких высоких давлений (135 ГПа), поскольку они не учитывают возможные фазовые переходы. Тем не менее впервые получены данные о возможности реакционного взаимодействия между металлическим ядром и субдуцирующим карбонатом кальция. Все фазы, обнаруженные в экспериментальных образцах при 6 ГПа, имеют стабильные полиморфные модификации на границе ядромантия. Карбонат кальция (арагонит) переходит в постарагонит, стабильный в диапазоне 40-137 ГПа [Ono et al., 2005; Oganov et al., 2006]. Са-вюстит не был изучен при высоких давлениях, но, по всей видимости, не образует отдельной фазы в нижней мантии. В структуре карбида $\mathrm{Fe}_{3} \mathrm{C}$ происходит магнитный переход со значительным уменьшением объема при 55-60 ГПа [Ono, Mibe, 2010; Litasov et al., 2013а]. Кроме того, вюстит и магнезиовюстит реагируют с $\mathrm{CO}_{2}$ в алмазной ячейке с лазерным нагревом при 40-105 ГПа с образованием фаз подобных ортокарбонатам с $\mathrm{Fe}^{3+}$ и с $\left(\mathrm{CO}_{4}\right)^{4-}$ тетраэдрами в структуре [Boulard et al., 2011, 2012].

Дальнейшие исследования системы $\mathrm{Fe}$-карбонат будут осуществлены в алмазной ячейке при $P$ $T$-параметрах, близких к условиям на границе ядро-мантия. Также будет рассмотрена кинетика реакции и получены зависимости константы реакции от времени и температуры.

Мы благодарим рецензентов за критические замечания к статье.

Работа выполнена при поддержке Российского научного фонда № 14-17-00601 и в рамках проекта Министерства образования и науки Российской Федерации № 14.В25.31.0032.

\section{ЛИТЕРАТУРА}

Добрецов Н.Л., Шацкий А.Ф. Глубинный цикл углерода и глубинная геодинамика: роль ядра и карбонатитовых расплавов в нижней мантии // Геология и геофизика, 2012, т. 53 (11), с. 1455-1475.

Жимулев Е.И., Чепуров А.И., Синякова Е.Ф., Сонин В.М., Чепуров А.А., Похиленко Н.П. Кристаллизация алмаза в системах $\mathrm{Fe}-\mathrm{Co}-\mathrm{S}-\mathrm{C}$ и $\mathrm{Fe}-\mathrm{Ni}-\mathrm{S}-\mathrm{C}$ и роль металл-сульфидных расплавов в генезисе алмазов // Геохимия, 2012, т. 50, с. 227-239. 
Литасов К.Д. Физико-химические условия плавления мантии Земли в присутствии $\mathrm{C}-\mathrm{O}-\mathrm{H}-$ флюида по экспериментальным данным // Геология и геофизика, 2011, т. 52 (5), с. 613 -635.

Логвинова А.М., Вирт Р., Томиленко А.А., Афанасьев В.П., Соболев Н.В. Особенности фазового состава наноразмерных кристаллофлюидных включений в аллювиальных алмазах северо-востока Сибирской платформы // Геология и геофизика, 2011, т. 52 (11), с. 1634-1648.

Похиленко Н.П., Агашев А.М., Литасов К.Д., Похиленко Л.Н. Взаимоотношения карбонатитового метасоматоза деплетированных перидотитов литосферной мантии с алмазообразованием и карбонатит-кимберлитовым магматизмом // Геология и геофизика, 2015, т. 56 (1-2), с. 361-383.

Рагозин А.Л., Каримова А.А., Литасов К.Д., Зедгенизов Д.А., Шацкий В.С. Содержание воды в минералах мантийных ксенолитов из кимберлитов трубки Удачная (Якутия) // Геология и геофизика, 2014, т. 55 (4), с. $549-567$.

Соболев Н.В., Ефимова Э.С., Поспелова Л.Н. Самородное железо в алмазах Якутии и его парагенезис // Геология и геофизика, 1981 (12), с. 25-29.

Соболев Н.В., Добрецов Н.Л., Отани Э., Тэйлор Л.А., Шертл Г.-П., Пальянов Ю.Н., Литасов К.Д. Проблемы, связанные с кристаллогенезисом и глубинным циклом углерода // Геология и геофизика, 2015, т. $56(1-2)$, с. 5-20.

Соколова Т.С., Дорогокупец П.И., Литасов К.Д. Взаимосогласованные шкалы давлений на основании уравнений состояния рубина, алмаза, $\mathrm{MgO}, \mathrm{B} 2-\mathrm{NaCl}$, а также $\mathrm{Au}, \mathrm{Pt}$ и других металлов до 4 Мбар и 3000 К // Геология и геофизика, 2013, т. 54 (2), с. 237-261.

Тэйлор Л.А., Ли Я. Включения сульфидов в алмазах не являются моносульфидным твердым раствором // Геология и геофизика, 2009, т. 50 (12), с. 1547-1559.

Федоров И.И., Чепуров А.И., Чепуров А.А., Куроедов А.В. Оценка скорости «самоочищения» алмазов от металлических включений в мантии Земли в посткристаллизационный период // Геохимия, 2005 , т. 42 , с. $1340-1344$.

Чепуров А.А., Федоров И.И., Сонин В.М. Экспериментальные исследования образования алмаза при высоких $P T$-параметрах (приложение к модели природного алмазообразования) // Геология и геофизика, 1998, т. 39 (2), с. 234-244.

Чепуров А.И., Жимулев Е.И., Сонин В.М., Чепуров А.А., Похиленко Н.П. О кристаллизации алмаза в металл-сульфидных расплавах // ДАН, 2009, т. 428, № 1, с. 101-103.

Чепуров А.И., Сонин В.М., Жимулев Е.И., Чепуров А.А., Томиленко А.А. Об образовании элементного углерода при разложении $\mathrm{CaCO}_{3}$ в восстановительных условиях при высоких $P$ - $T$-параметpax // ДАН, 2011, т. 441, № 6, с. 806-809.

Шацкий А.Ф., Борздов Ю.М., Сокол А.Г., Пальянов Ю.Н. Особенности фазообразования и кристаллизации алмаза в ультракалиевых карбонат-силикатных системах с углеродом // Геология и геофизика, 2002, т. 43 (10), с. 940-950.

Ballhaus C., Frost B.R. The generation of oxidized $\mathrm{CO}_{2}$-bearing basaltic melts from reduced $\mathrm{CH}_{4}$-bearing upper mantle sources // Geochim. Cosmochim. Acta, 1994, v. 58, p. 4931- 4940.

Bose K., Ganguly J. Quartz-coesite transition revisited - reversed experimental determination at 500 $1200{ }^{\circ} \mathrm{C}$ and retrieved thermochemical properties // Amer. Mineral., 1995, v. 80, p. 231-238.

Boulard E., Gloter A., Corgne A., Antonangeli D., Auzende A.L., Perrillat J.P., Guyot F., Fiquet G. New host for carbon in the deep Earth // Proceedings of the National Academy of Sciences of the United States of America, 2011, v. 108, p. 5184-5187.

Boulard E., Menguy N., Auzende A.L., Benzerara K., Bureau H., Antonangeli D., Corgne A., Morard G., Siebert J., Perrillat J.P., Guyot F., Fiquet G. Experimental investigation of the stability of Ferich carbonates in the lower mantle // J. Geophys. Res.-Solid Earth, 2012, v. 117, p. B02208, doi: 02210.0102/ $02011 \mathrm{jb} 008733$.

Dasgupta R. Ingassing, storage, and outgassing of terrestrial carbon through geologic time // Rev. Miner. Geochem., 2013, v. 75, p. 183-229.

Dasgupta R., Hirschmann M.M. Melting in the Earth's deep upper mantle caused by carbon dioxide // Nature, 2006, v. 440, p. 659-662.

Dasgupta R., Hirschmann M.M. The deep carbon cycle and melting in Earth's interior // Earth Planet. Sci. Lett., 2010, v. 298, p. 1-13.

Deines P., Harris J. Sulfide inclusion chemistry and carbon isotopes of African diamonds // Geochim. Cosmochim. Acta, 1995, v. 59, p. 3173-3188.

Foley S.F. A reappraisal of redox melting in the Earth's mantle as a function of tectonic setting and time // J. Petrol., 2011, v. 52, p. 1363-1391.

Frost D.J., McCammon C.A. The redox state of Earth's mantle // Ann. Rev. Earth Planet. Sci., 2008, v. 36, p. $389-420$. 
Grassi D., Schmidt M.W. The melting of carbonated pelites from 70 to $700 \mathrm{~km}$ depth // J. Petrol., 2011, v. 52 , p. $765-789$.

Gudfinnsson G.H., Presnall D.C. Continuous gradations among primary carbonatitic, kimberlitic, melilititic, basaltic, picritic, and komatiitic melts in equilibrium with garnet lherzolite at $3-8 \mathrm{GPa} / / \mathrm{J}$. Petrol., 2005 , v. 46, p. $1645-1659$.

Hayman P.C., Kopylova M.G., Kaminsky F.V. Lower mantle diamonds from Rio Soriso (Juina area, Mato Grosso, Brazil) // Contr. Miner. Petrol., 2005, v. 149, p. 430- 445.

Irving A.J., Wyllie P.J. Subsolidus and melting relationships for calcite, magnesite and the join $\mathrm{CaCO}_{3}-$ $\mathrm{MgCO}_{3}$ to $36 \mathrm{~Kb} / /$ Geochim. Cosmochim. Acta, 1975, v. 39, p. 35-53.

Kaminsky F. Mineralogy of the lower mantle: A review of 'super-deep' mineral inclusions in diamond // Earth-Sci. Rev., 2012, v. 110, p. 127-147.

Kaminsky F.V., Wirth R. Iron carbide inclusions in lower mantle diamond from Juina, Brazil // Can. Mineral., 2011, v. 49, p. 555-572.

Kennedy C.S., Kennedy G.C. The equilibrium boundary between graphite and diamond // J. Geophys. Res., 1976, v. 81, p. 2467-2470.

Kiseeva E.S., Yaxley G.M., Hermann J., Litasov K.D., Rosenthal A., Kamenetsky V.S. An experimental study of carbonated eclogite at 3.5-5.5 GPa: Implications for silicate and carbonate metasomatism in the cratonic mantle // J. Petrol., 2012, v. 53, p. 727-759.

Kiseeva E.S., Litasov K.D., Yaxley G.M., Ohtani E., Kamenetsky V.S. Melting phase relations of carbonated eclogite at 9-21 GPa and alkali-rich melts in the deep mantle // J. Petrol., 2013, v. 54, p. 15551583.

Komabayashi T., Fei Y.W. Internally consistent thermodynamic database for iron to the Earth's core conditions // J. Geophys. Res.-Solid Earth, 2010, v. 115, p. B03202, doi:03210.01029/02009jb006442.

Litasov K.D., Sharygin I.S., Dorogokupets P.I., Shatskiy A.F., Gavryushkin P.N., Sokolova T.S., Ohtani E., Li J., Funakoshi K. Thermal equation of state to $31 \mathrm{GPa}$ and $1473 \mathrm{~K}$ and thermodynamic properties of iron carbide, $\mathrm{Fe}_{3} \mathrm{C} / /$ J. Geophys. Res., v. 118, p. 5274-5284. 2013a, doi: 10.1002/2013JB010270.

Litasov K.D., Shatskiy A., Ohtani E., Yaxley G.M. Solidus of alkaline carbonatite in the deep mantle // Geology, 2013b, v. 41, p. 79-82.

Litasov K.D., Shatskiy A., Ohtani E. Melting and subsolidus phase relations in peridotite and eclogite systems with reduced COH fluid at 3-16 GPa // Earth Planet. Sci. Lett., 2014, v. 391, p. 87—99.

Logvinova A.M., Wirth R., Fedorova E.N., Sobolev N.V. Nanometre-sized mineral and fluid inclusions in cloudy Siberian diamonds: new insights on diamond formation // Eur. J. Mineral., 2008, v. 20, p. 317-331.

Lord O.T., Walter M.J., Dasgupta R., Walker D., Clark S.M. Melting in the Fe-C system to $70 \mathrm{GPa} / /$ Earth Planet. Sci. Lett., 2009, v. 284, p. 157-167.

Martirosyan N.S., Litasov K.D., Shatskiy A., Ohtani E. The reactions between iron and magnesite at $6 \mathrm{GPa}$ and $1273-1873 \mathrm{~K}$ : Implication to reduction of subducted carbonate in the deep mantle // J. Mineral. Petrol. Sci., 2015, v. 110. p. 49-59.

Nakajima Y., Takahashi E., Suzuki T., Funakoshi K. «Carbon in the core» revisited // Phys. Earth Planet. Int., 2009, v. 174, p. 202-211.

Oganov A.R., Glass C.W., Ono S. High-pressure phases of $\mathrm{CaCO}_{3}$ : Crystal structure prediction and experiment // Earth Planet. Sci. Lett., 2006, v. 241, p. 95-103.

Oganov A.R., Ono S., Ma Y.M., Glass C.W., Garcia A. Novel high-pressure structures of $\mathrm{MgCO}_{3}$, $\mathrm{CaCO}_{3}$ and $\mathrm{CO}_{2}$ and their role in Earth's lower mantle // Earth Planet. Sci. Lett., 2008, v. 273, p. 38 - 47.

Ono S., Mibe K. Magnetic transition of iron carbide at high pressures // Phys. Earth Planet. Int., 2010, v. 180, p. $1-6$.

Ono S., Kikegawa T., Ohishi Y., Tsuchiya J. Post-aragonite phase transformation in $\mathrm{CaCO}_{3}$ at $40 \mathrm{GPa} / /$ Amer. Mineral., 2005, v. 90, p. 667-671.

Ono S., Kikegawa T., Higo Y. In situ observation of a garnet/perovskite transition in $\mathrm{CaGeO}_{3} / /$ Phys. Chem. Miner., 2011, v. 38, p. 735-740.

Pal'yanov Y.N., Sokol A.G., Borzdov Y.M., Khokhryakov A.F., Sobolev N.V. Diamond formation from mantle carbonate fluids // Nature, 1999, v. 400, p. 417-418.

Pal'yanov Y.N., Sokol A.G., Borzdov Y.M., Khokhryakov A.F. Fluid-bearing alkaline carbonate melts as the medium for the formation of diamonds in the Earth's mantle: an experimental study // Lithos, 2002, v. 60, p. $145-159$.

Palyanov Y.N., Bataleva Y.V., Sokol A.G., Borzdov Y.M., Kupriyanov I.N., Reutsky V.N., Sobolev N.V. Mantle - slab interaction and redox mechanism of diamond formation // Proceedings of the National Academy of Sciences, 2013, v. 110, p. 20408-20413. 
Richardson S., Shirey S., Harris J., Carlson R. Archean subduction recorded by Re-Os isotopes in eclogitic sulfide inclusions in Kimberley diamonds // Earth Planet. Sci. Lett., 2001, v. 191, p. 257-266.

Rohrbach A., Schmidt M.W. Redox freezing and melting in the Earth's deep mantle resulting from carbon-iron redox coupling // Nature, 2011, v. 472, p. 209-212.

Safonova I., Litasov K., Maruyama S. Triggers and sources of volatile-bearing plumes in the mantle transition zone // Geosci. Front., 2015, doi:10.1016/j.gsf.2014.11.004.

Scott H.P., Williams Q., Knittle E. Stability and equation of state of $\mathrm{Fe}_{3} \mathrm{C}$ to $73 \mathrm{GPa}$ : Implications for carbon in the Earth's core // Geophys. Res. Lett., 2001, v. 28, p. 1875-1878.

Scott H.P., Hemley R.J., Mao H.-K., Herschbach D.R., Fried L.E., Howard W.M., Bastea S. Generation of methane in the Earth's mantle: in situ high pressure - temperature measurements of carbonate reduction // Proceedings of the National Academy of Sciences of the United States of America, 2004, v. 101, p. 1402314026.

Shatskiy A., Litasov K.D., Terasaki H., Katsura T., Ohtani E. Performance of semi-sintered ceramics as pressure-transmitting media up to $30 \mathrm{GPa} / /$ High Press. Res., 2010, v. 30, p. $443-450$.

Shatskiy A., Katsura T., Litasov K.D., Shcherbakova A.V., Borzdov Y.M., Yamazaki D., Yoneda A., Ohtani E., Ito E. High pressure generation using scaled-up Kawai-cell // Phys. Earth Planet. Int., 2011, v. 189, p. $92-108$.

Shatskiy A., Sharygin I.S., Gavryushkin P.N., Litasov K.D., Borzdov Y.M., Shcherbakova A.V., Higo Y., Funakoshi K., Palyanov Y.N., Ohtani E. The system $\mathrm{K}_{2} \mathrm{CO}_{3}-\mathrm{MgCO}_{3}$ at $6 \mathrm{GPa}$ and $900-1450{ }^{\circ} \mathrm{C} / /$ Amer. Mineral., 2013, v. 98, p. 1593-1603.

Shirasaka M., Takahashi E., Nishihara Y., Matsukage K., Kikegawa T. In situ X-ray observation of the reaction dolomite $=$ aragonite + magnesite at 900-1300 K // Amer. Mineral., 2002, v. 87, p. 922—930.

Shirasaka M., Takahashi E. A genesis of carbonatitic melt within subducting oceanic crust: high pressure experiments in the system $\mathrm{MORB}-\mathrm{CaCO}_{3} / / 8$ th International Kimberlite Conference Long Abstract, Victoria, Canada, 2003, p. 1-5.

Sokol A.G., Pal'yanov Y.N., Pal'yanova G.A., Khokhryakov A.F., Borzdov Y.M. Diamond and graphite crystallization from C-O-H fluids under high pressure and high temperature conditions // Diam. Relat. Mater., 2001, v. 10, p. 2131-2136.

Stagno V., Frost D.J. Carbon speciation in the asthenosphere: Experimental measurements of the redox conditions at which carbonate-bearing melts coexist with graphite or diamond in peridotite assemblages // Earth Planet. Sci. Lett., 2010, v. 300, p. 72-84.

Stagno V., Tange Y., Miyajima N., McCammon C.A., Irifune T., Frost D.J. The stability of magnesite in the transition zone and the lower mantle as function of oxygen fugacity // Geophys. Res. Lett., 2011, v. 38, p. L19309, doi: 19310.11029/12011g1049560.

Staudigel H. Chemical fluxes from hydrothermal alteration of the oceanic crust // Treatise on geochemistry (Second Edition) / Eds. K.K. Turekian, H.D. Holland. Oxford, Elsevier, 2014, p. 583 -606.

Suito K., Namba J., Horikawa T., Taniguchi Y., Sakurai N., Kobayashi M., Onodera A., Shimomura O., Kikegawa T. Phase relations of $\mathrm{CaCO}_{3}$ at high pressure and high temperature // Amer. Mineral., 2001, v. 86, p. 997-1002.

Syracuse E.M., van Keken P.E., Abers G.A. The global range of subduction zone thermal models // Phys. Earth Planet. Int., 2010, v. 183, p. 73-90.

Takahashi S., Ohtani E., Terasaki H., Ito Y., Shibazaki Y., Ishii M., Funakoshi K.-I., Higo Y. Phase relations in the carbon-saturated $\mathrm{C}-\mathrm{Mg}-\mathrm{Fe}-\mathrm{Si}-\mathrm{O}$ system and $\mathrm{C}$ and $\mathrm{Si}$ solubility in liquid $\mathrm{Fe}$ at high pressure and temperature: implications for planetary interiors // Phys. Chem. Miner., 2013, v. 40, p. 647-657.

Wood B.J., Li J., Shahar A. Carbon in the core: Its influence on the properties of core and mantle // Rev. Mineral. Geochem., 2013, v. 75, p. 231-250. 